\title{
Precarização e feminização do trabalho em Paraupebas, no estado do Pará
}

\author{
Casualization and feminization of labor in Paraupebas in the \\ state of Pará
}

Carla Rafaela Lemos Sales* Adriana de Azevedo Mathis**

\begin{abstract}
Resumo - Este artigo apresenta uma discussão sobre o processo de precarização social do trabalho, com destaque ao debate sobre o conceito de precariado e a inserção das mulheres no mercado de trabalho, a partir do aumento do desemprego em nível mundial e a intensificação de cursos de qualificação profissional. As análises teóricas são confrontadas com a realidade do município de Parauapebas (PA) através de um viés crítico-dialético, na análise dos discursos de trabalhadores desempregados que realizaram cursos de qualificação profissional pelo Pronatec e representantes do poder público municipal. Conclui-se que as tendências internacionais e locais da precarização são funcionais às estratégias de expansão do capital.

Palavras-chave: precarização social do trabalho; precariado; feminização do trabalho; Parauapebas.
\end{abstract}

\begin{abstract}
This article presents a discussion of the process of social casualization of labor, especially of the debate on the concept of precariat and the inclusion of women in the labor market, as the increase in unemployment worldwide and greater availability of professional training courses. The theoretical analyses are confronted with the reality of the municipality of Parauapebas, Pará through a criticaldialectical perspective, from the analysis of the speeches of unemployed workers who did professional training courses by Pronatec and of representatives of the municipal government. It is concluded that international and local casualization trends are functional to capital expansion strategies.
\end{abstract}

Keywords: social precarious work; precariat; feminization of work; Parauapebas

\footnotetext{
*Mestranda em Serviço Social pelo Programa de Pós-Graduação em Serviço Social da Universidade Federal do Pará (UFPA). Correspondência: Avenida Barão do Rio Branco, 1180, Nova Olinda. Castanhal - Pará. Cep: 68742000. Email:<crlsufpa06@gmail.com>.

** Doutora em Serviço Social (UFRJ). Bolsista da CAPES para realização de estágio pós-doutoral na Universidade Livre de Berlin/Alemanha (2014/2015). Professora e pesquisadora da Pós-graduação em Serviço Social da Universidade Federal do Pará. Correspondência: Travessa Nove de Janeiro, 1613/ apartamento 402, São Braz. Belém - Pará. Cep: 66060575. Email: <drika.azevedo@hotmail.com>
} 


\section{Introdução}

Análises realizadas acerca das atuais tendências mundiais e nacionais sinalizam a fragilidade na absorção de mão de obra no Brasil'. Diante desse quadro, nas localidades onde há maiores taxas de desemprego, observa-se como principal justificativa pelos representantes do poder público a crescente falta de profissionais qualificados e sem experiência para atender às necessidades do mercado. Destarte, os organismos internacionais, como a Organização Internacional do Trabalho (OIT), e instituições brasileiras, como o Instituto de Pesquisa Econômica Aplicada (Ipea), indicam um maior reforço no investimento em políticas para garantir o acesso ao mercado de trabalho, acompanhado de parcerias público-privadas (IPEA, 2010; OIT, 2010). No caso brasileiro, ganha destaque, nos últimos anos, o Programa Nacional de acesso ao Ensino Técnico e Emprego (Pronatec).

A relevância do programa e o discurso comum comparativo entre o desemprego e a falta de qualificação profissional também são reforçados no município de Parauapebas ${ }^{2}$, situado a sudeste do estado do Pará. Conhecido pelo seu potencial atrativo em relação ao trabalho, devido à estreita vinculação com a empresa transnacional Vale ${ }^{3}$, as indicações de absorção de mão de obra no município revelam um quadro negativo ${ }^{4}$.

A partir da pesquisa realizada, identificam-se os diversos discursos ${ }^{5}$ encontrados em Parauapebas, seja pela empresa transnacional, seja por representantes do poder público local. Esses discursos refletem superficialidade e incompletude e, portanto, não correspondem à essência do fenômeno sobre o desemprego na região. Assim, a realidade local parauapebense foi percebida como vinculada às tendências internacionais que remetem a um processo de precarização social do trabalho.

Na sequência, o artigo apresenta uma discussão acerca desse processo, dando destaque para o debate sobre o conceito de precariado e a inserção das mulheres no mercado de trabalho, já que ambas as discussões estão em consonância com a realidade dos trabalhadores desempregados de Parauapebas, que se tornaram sujeitos da pesquisa. Percebe-se, no muni-

\footnotetext{
${ }^{1}$ Vide dissertação de mestrado intitulada Desemprego e qualificação profissional em Parauapebas no estado do Pará, do Programa de Pós-Graduação de Serviço Social do Instituto de Çiências Sociais Aplicadas, da Universidade Federal do Pará, apresentada em junho de 2015.

${ }^{2}$ O município de Parauapebas nasceu em 1988. Porém, o território, situado no sudeste do Pará, já existia e cresceu com a instalação de grandes projetos para a extração de recursos naturais, como o Projeto Grande Carajás, conduzido pela Companhia Vale do Rio Doce (hoje Vale), e a extração de ouro em Serra Pelada..

${ }^{3}$ A empresa Vale, uma das maiores no ramo de extração mineral do mundo, relaciona suas atividades à estrutura socioeconômica-ambiental dos municípios de Curionópolis, Eldorado dos Carajás, Canaã dos Carajás e Parauapebas (MATHIS; MATHIS, 2012).

${ }^{4}$ O MTE (2014), por exemplo, indica diminuição de 34\% na admissão de mão de obra no setor de extração mineral (atividade principal parauapebense) entre os anos de 2010 e 2013.

${ }^{5}$ Ressalta-se que a técnica utilizada para a averiguação das entrevistas e informações coletadas se deu através da análise do discurso. $\mathrm{O}$ intuito era perceber a linguagem exposta em sua multiplicidade, sem descartar nenhum discurso oferecido pelo sujeito, analisando como as relações de poder estão presentes nesses enunciados. Ver: Bakhtin (2010), Brandão (2012).
} 


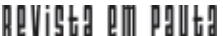

\} PRECARIZAÇÃO E FEMINIZAÇÃO - SALES, C. R. L.; MATHIS, A. A. \}

DOI: $10.12957 /$ rep.2015.21053

cípio, alta discriminação em relação ao trabalho feminino e à presença maciça das mulheres nos cursos de qualificação profissional.

Para a realização da pesquisa in loco foram destinados 15 dias. Houve seis entrevistas com representantes do poder público municipal que atuam diretamente na administração e articulação do processo, que vai da formação profissional ao encaminhamento e inserção no mercado de trabalho. $\mathrm{O}$ intuito era obter informações dos trabalhadores sobre as necessidades atendidas com os programas de qualificação profissional.

Por meio de contato telefônico, os trabalhadores foram convidados para a realização de entrevistas. A partir disso, constatou-se haver um grande número de trabalhadores desempregados que tinham recebido qualificação profissional no Centro de Inclusão Produtiva, local onde são realizados os cursos ministrados pelos organismos do Sistema S, em especial o Serviço Nacional de Aprendizagem Industrial (Senai), através do Pronatec ${ }^{6}$. Após o contato via telefone, realizaram-se 14 entrevistas (11 homens e 3 mulheres).

É importante destacar que o caminho teórico-metodológico da investigação conduziu o trabalho para alguns achados, especialmente os dados concernentes à inserção precária das mulheres no mercado de trabaIho. As informações obtidas anteriormente à alta discriminação do trabalho feminino na localidade não consideravam a precarização sofrida por esse público. Além disso, ao ser detectada a forte presença de mulheres nos cursos de qualificação profissional, e com os densos relatos das trabalhadoras entrevistadas, chamou a atenção que esse fato precisava ser mais detalhado e aprofundado para, assim, melhor delimitar o perfil dos trabalhadores, incluindo ambos os sexos.

Nessa perspectiva, este artigo apresenta, inicialmente, uma discussão acerca da precarização social do trabalho, que permite apreender o emprego, desemprego e qualificação profissional imersos nas tendências internacionais, nacionais e regionais do mercado de trabalho, refletindo na realidade local do município de Parauapebas. Em seguida, apontam-se notas introdutórias sobre o conceito de precariado, levando em consideração as características encontradas nos sujeitos da pesquisa. Por fim, aborda-se o processo de feminização do trabalho no contexto de precarização, diante das informações coletadas em campo, apontando as informações obtidas com os entrevistados.

Finalmente, as conclusões da pesquisa ratificam que a particularidade de Parauapebas compreende tendências mundiais do mercado de trabalho, associadas à funcionalidade histórica da região e da localidade para a expansão de produção e lucratividade, demonstrando que a expulsão de trabalhadores desse mercado é funcional à expansividade da trans-

\footnotetext{
${ }^{6}$ Relata-se que alguns entrevistados não conseguiram comparecer, pois a maioria encontrou dificuldades diante da condição de precariedade em que vivem: ou iam para a entrevista ou garantiam mais um serviço ("bico") para o sustento daquele dia. Importa sinalizar que a maior parte dos cursos ofertados está diretamente voltada às atividades da empresa Vale.
} 


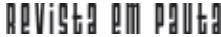

\} PRECARIZAÇÃO E FEMINIZAÇÃO - SALES, C. R. L.; MATHIS, A. A. \}

DOI: $10.12957 /$ rep.2015.21053

nacional Vale. Essa afirmação é reiterada na análise dos discursos obtidos com as entrevistas, pois não se encontra reflexão e questionamentos críticos acerca das diretrizes apontadas pelos organismos internacionais e nacionais, mas reafirmação de um conteúdo ideológico hegemônico de perpetuação e expansão do capital.

\section{O debate marxista sobre a precarização social do trabalho}

Neste item, cabe ressaltar como as tendências internacionais, nacionais e regionais do mercado de trabalho estão inseridas nos processos de precarização que influenciam a realidade local do município de Parauapebas ${ }^{7}$. Importa sinalizar que os autores abaixo relacionados referem-se, de forma direta ou indireta, ao debate marxista sobre o trabalho assalariado, levando em consideração a formação de um excedente de trabalhadores às necessidades do capital, que vem a ser chamado por Marx (2013) de exército industrial de reserva. Para o autor, o excedente de trabalhadores se torna funcional ao modo de produção capitalista e, consequentemente, à acumulação de capital, pois

se uma população trabalhadora excedente é um produto necessário da acumulação ou do desenvolvimento da riqueza com base capitalista, essa superpopulação se converte, em contrapartida, em alavanca da acumulação capitalista. Ela constitui um exército industrial de reserva disponível, que pertence ao capital de maneira tão absoluta como se ele o tivesse criado por sua própria conta. Ela fornece as suas necessidades variáveis de valorização o material humano sempre pronto para ser explorado, independentemente dos limites do verdadeiro aumento populacional. (MARX, 2013, p. 707 - grifos nossos).

Tal excedente se reflete em seu caráter crônico e imensurável crescimento de massas de desempregados em nível global na atualidade. Desse modo, revela que, ao estar atrelada de forma intrínseca à crise estrutural do capitalismo, especialmente à última do século XX, a superpopulação de trabalhadores se espelha, em todos os âmbitos, no mercado de trabalho através da flexibilidade e precarização do trabalho, assim como as consequências e manifestações destes, como a informalidade, a terceirização e a inserção precária feminina no mercado de trabalho.

Nessa perspectiva, Alencar e Granemann (2009), ao discorrerem acerca da configuração do trabalho no capitalismo contemporâneo, percebem a vinculação estreita do uso intensivo da força de trabalho, através da sua superexploração, com o aumento exigente e característico da pro-

\footnotetext{
${ }^{7}$ Ver artigo de Sales e Mathis (2015), intitulado Desemprego e qualificação profissional na região de Carajás-Pará, publicado na área de temas livres da revista Argumentum. Este artigo apresenta uma análise sobre a relação entre o crescente número de trabalhadores desempregados, na região de Carajás, no município de Parauapebas, excluídos dos bens e serviços sociais, bem como a presença marcante da transnacional Vale na localidade.
} 


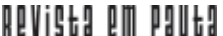

\} PRECARIZAÇÃO E FEMINIZAÇÃO - SALES, C. R. L.; MATHIS, A. A.

DOI: $10.12957 /$ rep.2015.21053

dutividade e lucratividade. Por isso, aprofundam-se as contradições intrínsecas nesta sociedade, especialmente a partir da flexibilização de direitos trabalhistas. Nesse sentido, a regulação social do mercado é submetida, em tempos de financeirização do capital, a determinados interesses que movem a intervenção estatal, de forma oposta aos trabalhadores, com a produção de supérfluos de contingentes de mão de obra. Para as autoras, o desemprego é, dessa forma, uma das manifestações da atual configuração do capitalismo mundial, subsidiado por conceitos ideológicos que camuflam a essência contraditória desta sociedade.

Para Antunes (2009), especialmente a partir da década de 1970, com o processo de reestruturação produtiva surgem novas formas complexas e contraditórias de organização e controle do trabalho, que o conduzem à difusão global da precarização. Isto porque há uma multiplicação das atividades salariais, fazendo com que emerja a classe-que-vive-do-trabaIho, composta por todos aqueles (homens e mulheres) que vendem sua força de trabalho sem serem os donos de seus meios de produção. Na era da cibernética, tal processo tende a atingir todos os contingentes de trabalhadores, manifestando-se, por exemplo, através do empreendedorismo, cooperativismo e trabalho voluntário. Ao invés de serem iniciativas de organizações de trabalhadores, passam a ser incentivados pelas empresas em prol de suas respectivas necessidades, manifestadas, sobretudo, por meio da difusão da flexibilização do trabalho. Provocam: aumento da instabilidade no trabalho; terceirização e subcontratação; aumento do número de mulheres no mercado de trabalho, porém com remunerações mais baixas em relação aos homens; inchaço de trabalhadores no setor de serviços; exclusão dos jovens do mercado de trabalho e consequente inclusão no desemprego estrutural e característico da sociedade capitalista; exclusão de trabalhadores com idade próxima aos quarenta anos, os quais, uma vez desempregados, dificilmente conseguem se inserir em nova atividade; aumento de trabalho infantil; crescimento de instituições do terceiro setor, como as ONGs; e crescimento do trabalho em domicílio que, atrelado ao trabalho doméstico, aprofunda a exploração do trabalho feminino.

Levando em consideração as diversas formas de organização e controle do trabalho existentes no decorrer do amadurecimento da sociedade capitalista, Druck (2011) percebe a precarização social do trabalho numa relação de continuidade entre o velho e o novo, que se metamorfoseia e ao mesmo tempo não abandona o seu conteúdo. Dessa forma, a autora apresenta como este processo se configura enquanto estratégia de dominação do capital, especialmente nesta fase de financeirização da economia de cunho neoliberal e aspectos flexíveis de acumulação, que desencadearam profundas modificações reestruturantes da produção e do trabalho a partir da década de 1970.

Destarte, assim como em outras fases do capitalismo, o intuito é sempre a expansão do lucro através de diversificadas formas de exploração 


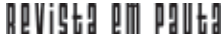

\} PRECARIZAÇÃO E FEMINIZAÇÃO - SALES, C. R. L.; MATHIS, A. A.\}

DOI: 10.12957/rep.2015.21053

do trabalho. Contudo, é na atual etapa que ela se torna cada vez mais intensa através do alto desenvolvimento tecnológico. Como consequência, identificam-se, na realidade, o crescimento do desemprego e das diversas formas de precarização do trabalho, como, por exemplo: a) vulnerabilidade estrutural na inserção do mercado de trabalho, que produz mais desigualdades sociais; b) intensificação do trabalho, com metas inalcançáveis e formação de um perfil de trabalhador polivalente, além do processo de terceirização, que estimula maior produtividade; c) péssimas condições de saúde e insegurança no trabalho, pois a preocupação das empresas é como isso pode implicar na produção; d) não reconhecimento dos trabalhadores enquanto classe ou coletivo e, da mesma forma, perda de identidade individual; e) consequente fragilização das organizações e representações de trabalhadores; f) e perdas de direitos trabalhistas.

\section{Sobre o conceito de precariado: notas introdutórias}

A partir do trabalho realizado, observa-se uma aproximação do perfil dos sujeitos entrevistados na pesquisa com o conceito de "precariado" desenvolvido por determinados autores da Sociologia do Trabalho. Nesse sentido, apresentam-se, a seguir, notas introdutórias sobre o debate em torno da precarização do trabalho. Além disso, sinaliza-se a tentativa de definição, por parte de alguns autores, de um conceito de "precariado", que até o momento não apresenta consenso na literatura e gera inúmeras controvérsias.

Nessa perspectiva, Castel $\left(2013\right.$, p. 23) ${ }^{8}$ afirma que, para compreender a realidade atual, faz-se necessário dimensionar o novo dado contemporâneo:

a presença, aparentemente cada vez mais insistente, de indivíduos, colocados em situação de flutuação na estrutura social e que povoam, seus interstícios sem encontrar um lugar designado. Silhuetas incertas, a margem do trabalho e nas fronteiras das formas de troca socialmente consagradas - desempregados por período longo, moradores dos subúrbios pobres, beneficiários da renda mínima de inserção, vítimas das readaptações industriais, jovens a procura de emprego e que passam de estágio a estágio, de pequeno trabalho a condição provisória... - quem são eles, de onde vem, como chegaram ao ponto em que estão, o que vão se tornar?

O foco da pesquisa do autor não está entre os mais ricos ou mais pobres e, sim, na relação existente entre precariedade econômica e instabilidade social. Nesse sentido, o autor aborda temáticas tais como precariedade, exclusão e segregação, pois entende que, na contemporaneidade,

${ }^{8}$ Vide o livro de R. Castel (2013), As metamorfoses da questão social, publicado na França em 1998. 


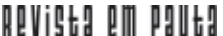

\} PRECARIZAÇÃO E FEMINIZAÇÃO - SALES, C. R. L.; MATHIS, A. A. \}

DOI: $10.12957 /$ rep.2015.21053

estão cada vez mais esgarçadas as zonas de coesão social marcadas por trabalho estável e que, na sociedade industrial do passado, sobretudo para as classes populares, estas caracterizavam áreas de integração. Nesse novo cenário, ao mesmo tempo em que se reduz a quantidade de trabalhadores permanentes, qualificados e protegidos, aumenta-se o número de trabalhadores subcontratados, subqualificados, mal pagos, mal protegidos, desempregados e trabalhadores em tempo parcial.

Conforme Castel (2013), para responder às novas exigências tecnológico-econômicas do capitalismo atual, identificam-se dois movimentos. Estes estão interligados e fazem parte de um processo de precarização do trabalho que dá margem para pensar numa "nova questão social": de um lado, a desestabilização dos trabalhadores estáveis (parte do operariado e parcela da pequena classe média está ameaçada de oscilação); de outro, a constituição e instalação da precarização do emprego e aumento do desemprego (com déficit de lugares ocupáveis na estrutura social). Ou seja, uma população ativa para o trabalho é colocada em condições de inatividade.

Na sociedade atual existe, de acordo com Castel (2013, p. 531), uma multiplicação de indivíduos que ocupam uma posição de "supranumerários", "inempregáveis" ou empregados de modo precário intermitente. Segundo o autor, os supranumerários são "pessoas inúteis para o mundo", e essa "inutilidade social" os desqualifica no plano cívico e político pois eles "podem escolher entre a resignação e a violência esporádica, a raiva", apesar disso, "a identidade pelo trabalho está perdida". Além disso, registrase a ausência de participação em qualquer atividade produtiva e isolamento relacional, o que produz "desfiliação"

No capitalismo globalizado, para Castel (2013), assim como para Standing ${ }^{10}$ (2013), a tese da flexibilidade do mercado laboral por conta das exigências mercadológicas cristalizou-se e tornou-se algo naturalizado na sociedade atual; por conta desse fenômeno, cresce o número de trabalhadores precarizados. Portanto, a ideia da flexibilidade está associada ao aumento sistemático da insegurança dos desempregados. Assim, faz-se necessário, cada vez mais, compreender o precariado apresentado como essa "nova classe perigosa", e torna-se urgente desvendar inúmeras questões que têm a ver com a manifestação do fenômeno na realidade.

Segundo Standing (2013), o precariado não se refere à classe média espremida nem a uma subclasse (underclass), e não é a camada inferior da classe trabalhadora. Para o autor, o precariado é um fenômeno novo,

\footnotetext{
${ }^{9}$ Castel (2013) prefere utilizar o termo "desfiliação" em vez de "exclusão". Destarte, desfiliação é sinônimo de dissociação, desqualificação ou invalidação social. Em paralelo aos trabalhadores "excluídos", "desfiliados", estão os trabalhadores estáveis desestabilizados e qualificados que se tornaram precários e os quadros bem considerados que podem ficar desempregados.

${ }_{10}$ Apesar de Standing (2013) escrever a primeira edição inglesa de The precariat, em 2011, e a edição espanhola, em 2013, portanto mais de uma década após a publicação de As metamorfoses da questão social, de Castel (2013), os dois autores compartilham as mesmas preocupações em torno da necessidade de definição de um conceito de "precariado" na atualidade.
} 


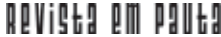

\} PRECARIZAÇÃO E FEMINIZAÇÃO - SALES, C. R. L.; MATHIS, A. A. \}

DOI: $10.12957 /$ rep.2015.21053

distinto da classe trabalhadora, tal como evidenciou Marx através do conceito de proletariado. Nesse sentido, o precariado refere-se a todos aqueles que levam uma existência precária, um grupo social e econômico com características próprias, uma classe em processo de formação e, por último, não uma classe para si, no sentido marxista do termo.

O autor apreende, ainda, que o precariado é uma classe em formação e, para se tornar uma classe para si, faz-se necessário, em curto e longo prazo, responder determinadas demandas, tais como: controle sobre o seu tempo; participação e acesso à esfera coletiva; desenvolvimento de suas capacidades no sentido de uma ética da solidariedade; acesso a direitos, segundo um regime internacional de direitos; visão de uma sociedade e ócio criativo; pensamento sobre um novo tipo de organismo coletivo e novo significado da liberdade de associação; luta por segurança econômica; e garantia de espaços de qualidade, conhecimento e gestão de riscos. Desse modo, o precariado não pode ser descrito apenas como um neologismo que combina o adjetivo "precário" e o substantivo "proletário".

Standing (2013) afirma que é possível distinguir vários grupos sociais que estão inseridos nas diversas classes sociais, que compreendem desde as elites, os executivos, os profitécnicos e os trabalhadores normais, até os mais precarizados ${ }^{11}$. O autor argumenta que o precariado carece de uma identidade profissional baseada no trabalho. Dessa maneira, este se ressente de uma sensação de pertencimento a uma comunidade ocupacional baseada em práticas estáveis, códigos éticos, normas de comportamento e direitos civis, sociais, culturais, econômicos e políticos.

Assim, apesar de o precariado não ser um grupo homogêneo, pode-se registrar, de forma geral, os principais grupos que o compõem: 1) trabalhadores com empregos sem proteção e empregos temporários; 2) trabalhadores em tempo parcial; 3) trabalhadores da área de telecomunicações que trabalham em centros de chamada; 4) e estagiários. A maioria desses trabalhadores convive com uma situação de instabilidade; tem uma relação com o trabalho de forma instrumental, oportunista e insegura.

O crescimento do precariado tem a ver com a terceirização, flexibilização e multifuncionalidade própria do atual estágio do capitalismo, no qual a globalização de caráter neoliberal é sinônimo de mercantilização e envolve aspectos da vida social, como família, escola, empresas, local de trabalho, política de proteção social, associações profissionais e políticas. Desse modo, os trabalhadores precarizados vivem em constante sensação de ansiedade, carecem de autoestima, não atribuem valor ao seu trabalho, sentem falta de uma profissão definida e constituem mão de obra itinerante

\footnotetext{
${ }^{11}$ O autor discorda da forma como o termo foi utilizado pelos sociólogos franceses, na década de 1980, usando-o para se referir a trabalhadores temporais. Além disso, não partilha da mesma opinião dos teóricos alemães que utilizaram este termo para sinalizar os trabalhadores temporais e os desempregados, sem esperanças de integração social. Não se trata, também, de trabalhadores pobres, conforme estudiosos japoneses, para indicar empregos inseguros.
} 


\section{Revigta [II paltg}

\} PRECARIZAÇÃO E FEMINIZAÇÃO - SALES, C. R. L.; MATHIS, A. A. \}

DOI: $10.12957 /$ rep.2015.21053

e sem representação sindical, sob subcontratação ou contratos temporários, com carência generalizada de proteção social.

Importa, ainda, destacar que Standing (2014) também discorre sobre a presença das mulheres no processo de precarização do trabalho sob um forte caráter da flexibilização, apontando para o fato de elas ingressarem mais rapidamente no precariado, juntamente com os jovens. Essa coincidência, seja como causa ou efeito, revela a desproporcionalidade de empregos precários, em que grande parte da força de trabalho das mulheres se encontra, por exemplo, em trabalho de tripla jornada (tarefas domésticas e trabalho assalariado), empregos temporários e com baixa remuneração ${ }^{12}$.

Ao analisar o conceito de precariado, Braga ${ }^{13}$ (2012) nota que este se distingue tanto do que define a sociologia francesa, particularmente o trabalho de Castel, escrito em 1998, que enfatiza o conceito de precariado a partir de sua condição de trabalhador temporário, quanto da apropriação do conceito desenvolvida pela sociologia inglesa, principalmente o trabalho de Standing, de 2011.

Para Braga (2012, p. 16), os dois autores anteriormente citados "compartilham a mesma compreensão sociológica, segundo a qual a precariedade corresponderia a uma condição exterior à relação salarial". Como diz o autor, "ao contrário, entendemos que em decorrência da mercantilização do trabalho, do caráter capitalista da divisão do trabalho e da anarquia da reprodução do capital, a precariedade é constitutiva da relação salarial". Desse modo, Braga (2012, p. 16) tece críticas aos autores, pois eles "identificaram erroneamente a particularidade da cidadania fordista com a totalidade da relação salarial".

Na concepção de Braga (2012), o precariado é o proletariado precarizado. Diferentemente de Marx, que utilizava o conceito de superpopulação relativa para se referir ao proletariado extremamente precarizado, o autor pretende abordar a dimensão subjetiva do precariado, enfatizando a angústia e inquietação próprias desse segmento social. Na opinião do autor, "o precariado, isto é o proletariado precarizado, é formado por aquilo que, excluídos tanto o lupemproletariado quanto a população pauperizada, Marx chamou de população relativa" (BRAGA, 2012, p. 18). Dessa maneira, deve-se diferenciar analiticamente o precariado do pauperismo (e o lupemproletariado) como também distingui-lo dos setores profissionais, grupos qualificados mais bem remunerados e estáveis da classe trabalhadora.

Como diz Braga (2012, p. 18), "o precariado faz parte integrante da classe trabalhadora, está no coração do próprio modo de produção capitalista e, a precariedade é uma dimensão intrínseca ao processo de mercantilização do capital". Nesse caso, a condição de precariedade se constitui

\footnotetext{
${ }^{12}$ É interessante a colocação do autor sobre uma maior probabilidade de encontrar mulheres com salários maiores que seus companheiros, em uma situação de precariedade, em relação aos homens casados com salários maiores que suas companheiras.

${ }^{13}$ Vide o livro A política do precariado: do populismo à hegemonia, de Ruy Braga (2012).
} 


\section{peVistg a}

\} PRECARIZAÇÃO E FEMINIZAÇÃO - SALES, C. R. L.; MATHIS, A. A.\}

DOI: 10.12957/rep.2015.21053

como um traço estrutural do capitalismo brasileiro. Assim, os trabalhadores precarizados são principalmente trabalhadores jovens, não qualificados ou semiqualificados e precarizados, recebendo em média $1 \frac{1}{2}$ do salário mínimo, inseridos em relações trabalhistas que dificultam sua organização coletiva.

Vale a pena ressaltar que, apesar de os autores acima referenciados apresentarem posições por vezes divergentes sobre a atual configuração dos trabalhadores precarizados, eles refletem de alguma maneira traços da realidade observada no município de Parauapebas. Contudo, a nosso ver, a análise de Braga (2012) é a que mais se aproxima da realidade efetivamente vivenciada por esses trabalhadores no município.

\section{A feminização do trabalho no processo de precarização do trabalho no município de Parauapebas}

Na pesquisa realizada no município de Parauapebas observa-se a precarização e feminização no processo do trabalho, especialmente no que diz respeito às mulheres negras. Tal processo contém características de um contexto histórico e social de submissão feminina em relação ao homem, somadas ao acirramento e difusão da precarização do trabalho. A conjunção desses dois fatores tende a gerar impactos na vida de mulheres e acentuar a dupla (às vezes tripla) jornada de trabalho (conciliação entre atividade no mercado de trabalho e trabalho doméstico).

De acordo com o documento da OIT (2010, p. 12) sobre "o perfil dos trabalhadores e trabalhadoras na economia informal", de 2010, identifica-se uma maior aceitação da flexibilidade ${ }^{14}$, especialmente pelas mulheres, "que se adaptam mais facilmente a este tipo de emprego e aceitam salários inferiores devido à sua necessidade de conjugar o trabalho profissional com o doméstico". Dessa forma, considerando o perfil dos trabalhadores e trabalhadoras na economia informal, o documento destaca o sexo e a cor da pele como fatores determinantes para a inserção no mercado de trabalho, principalmente no setor de serviços de baixa remuneração.

Nesse sentido, Abreu (1994) propõe uma ampla e profunda discussão sobre a flexibilização e sua influência nas relações de gênero no mundo do trabalho, revelando um vínculo intrínseco entre estes e pontuando a necessidade de compreender os impactos das concepções flexíveis de forma diferenciada para homens e para mulheres. Isto porque as mulheres começam a entrar mais no mercado de trabalho e, além de sofrerem as requisições acima descritas, passam a enfrentar, também nesse ambiente, as concepções da divisão sexual que segrega e impõe a mesma lógica pre-

\footnotetext{
${ }^{14}$ Sobre a flexibilização do trabalho, o documento aponta o que alegam as empresas sobre os altos custos para manter status de formalidade e, com isso, a adoção de medidas flexíveis na contratação e gestão do trabalho, retirando o caráter de confiança e durabilidade.
} 


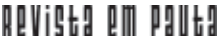

\} PRECARIZAÇÃO E FEMINIZAÇÃO - SALES, C. R. L.; MATHIS, A. A. \}

DOI: $10.12957 /$ rep.2015.21053

sente na família. Entretanto, para a autora, o argumento de forma isolada da segregação sexual no mercado de trabalho não compreende a totalidade da realidade. Para fugir de uma visão determinista, ela recomenda pensar a participação feminina no mercado de trabalho que contemple a discussão de gênero e classe.

Na mesma linha de pensamento, Hirata e Kergoat (2007) conceituam a divisão sexual do trabalho propondo-se a ir além da comumente conhecida, apresentando características da designação histórica da função produtiva aos homens e a função reprodutiva às mulheres. Sobre o assunto, as autoras pontuam ${ }^{15}: 1$ ) o surgimento e o desenvolvimento de "nomadismos sexuados", com a precarização e a flexibilização do emprego, pois verificase "que a divisão sexual do trabalho amolda as formas do trabalho e do emprego e, reciprocamente, que a flexibilização pode reforçar as formas mais estereotipadas das relações sociais de sexo" (HIRATA; KERGOAT, 2007, p. 600); 2) diante disso, o emprego feminino passa a ser priorizado no mercado de trabalho; 3 ) e há um aumento do tempo de trabalho das mulheres, o que significa que, para o trabalho doméstico, são designadas outras muIheres, de forma paga, gerando aquelas que são mais e menos precarizadas em um quadro de precariedade.

Recentemente, Hirata (2009) dimensiona, de forma específica, como as mulheres são especialmente atingidas pela precarização através da fragilização dos contratos pela flexibilidade, como o trabalho em tempo parcial. Além disso, aponta para o fato de que elas ocupam empregos temporários com mais facilidade, principalmente as jovens e menos qualificadas, bem como são tendencialmente conduzidas à precarização. Nesse sentido, a autora pontua que a globalização impactou incisivamente na precarização do trabalho feminino.

O que resta a analisar de modo mais geral - e cuja importância é proporcional à internacionalização atual do fenômeno - é a situação particular das mulheres no trabalho assalariado contemporâneo, as quais usufruem (mesmo que isso deva ser modulado conforme as categoriais sociais e os contextos nacionais) de uma maior autonomia e mais liberdade no casal e na família devido à sua maior independência econômica, ocupam uma minoria significativa de empregos executivos e de profissões intelectuais superiores, embora sejam, ao mesmo tempo, majoritariamente mais vulneráveis e menos legítimas do que os homens no espaço profissional. (HIRATA, 2009, p. 29).

Verifica-se, dessa forma, que a feminização do trabalho teve um significado reconvertido aos interesses de acumulação do capitalismo. A presença da mulher, controlada pela divisão sociossexual do trabalho, torna-

\footnotetext{
${ }^{15}$ Ao se proporem a discutir sobre as novas configurações da divisão sexual do trabalho, em especial a partir das últimas décadas do século XX, as autoras relembram uma realidade cada vez mais frequente no Brasil, apesar de se referirem ao contexto europeu, em especial o francês.
} 


\section{ReVistg a}

\} PRECARIZAÇÃO E FEMINIZAÇÃO - SALES, C. R. L.; MATHIS, A. A. \}

DOI: 10.12957/rep.2015.21053

se um grande desafio de superação, especialmente por ter adquirido características de uma das peças fundamentais na produtividade e competitividade.

Diante do exposto, verifica-se que há ligação estreita entre a realidade de precarização do trabalho no local pesquisado, no município de Parauapebas, e a conjuntura mundial do modo de produção capitalista. Neste contexto, destaca-se a feminização no processo de precarização do trabalho e apontam-se alguns dados a partir das falas de trabalhadoras desempregadas entrevistadas, em que é possível correlacionar a realidade local com as tendências mundiais e internacionais do trabalho.

Nas matrículas realizadas de janeiro a setembro de 2014, segundo sexo, no Centro de Inclusão Produtiva, empiricamente constata-se que, do total, $49 \%$ são trabalhadores desempregados, sendo que a maioria são muIheres, ainda que seja pequena a diferença em relação aos homens: de 648 matrículas, 340 correspondiam ao público feminino. No que se refere à renda familiar, nota-se que cerca de $60 \%$ possuem renda familiar entre zero e um salário mínimo e meio, revelando alta vulnerabilidade à pobreza desses trabalhadores e suas respectivas famílias ${ }^{16}$. Assim, sobretudo as muIheres são aquelas que se encontram em maior condição de vulnerabilidade.

Levando em consideração que os cursos ofertados pelo programa estão diretamente vinculados a um mercado de trabalho parauapebense essencialmente de âmbito privado (seja em pequenas, médias ou grandes empresas), é possível fazer uma comparação com os dados da OIT (2010), que revelam uma menor renda feminina em detrimento da masculina nesses espaços de trabalho. Ademais, chama a atenção o fato de que quase $68 \%$ dos matriculados não recebem nenhum tipo de benefício de programa social, quando $60 \%$ possuem uma significativa renda familiar baixa, sendo que as mulheres são maioria em condição de exposição à pobreza.

A partir dessas informações, é possível visualizar influências da precarização social do trabalho no município de Parauapebas, especialmente com a forte tendência para a feminização do trabalho. Percebe-se, também, que a maior busca de mulheres por cursos de qualificação profissional, nos moldes dos interesses de expansividade da empresa transnacional Vale, na região, tende a inserir esse público de forma precária no mercado de trabalho.

De uma forma geral, observa-se, no perfil dos trabalhadores e trabalhadoras entrevistados, determinadas características comuns ${ }^{17}$ : a) experiência em trabalhos temporários, que facilita a entrada na informalidade; b) dificuldade de se projetar em uma profissão pela ausência de qualificação exigida para serem profissionais; c) demanda do mercado de trabalho por

\footnotetext{
${ }^{16}$ Valor Nacional para o salário mínimo no ano de 2014: R\$ 724,00.

17 Importa sinalizar que o perfil e o processo de escolha dos sujeitos entrevistados, assim como a orientação metodológica da pesquisa, já foram evidenciados anteriormente na Introdução.
} 


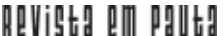

\} PRECARIZAÇÃO E FEMINIZAÇÃO - SALES, C. R. L.; MATHIS, A. A. )

DOI: $10.12957 /$ rep.2015.21053

experiência profissional com registro em carteira de trabalho, dificultando a inserção profissional do indivíduo; d) extensa jornada de trabalho, sem contestação por parte dos entrevistados; e) identificação do crescimento do desemprego a partir de $2012 ;$ f) indicação de longo período para encontrar emprego formal e dificuldade de encontrar trabalho informal; g) ausência de experiência sindical e descrédito em relação à representatividade do sindicato; h) percepção de que a qualificação não é garantia para conquista de emprego, tendência à individualização do problema e necessidade de maiores esforços pessoais para conseguir trabalho; i) relatos de inspiração na religião e apoio em familiares e pessoas amigas; j) registro de acúmulo de certificados sem efeito na realidade prática; j) indicação de aceitação de qualquer tipo de emprego, com ou sem carteira assinada; k) identificação de não acesso à internet; m) condição de desemprego, na maioria das vezes, expressa em sentimentos de tristeza, stress, perda de sono, impaciência, impotência, fracasso, ansiedade, angústia, incapacidade, desespero, exclusão e agonia; I) e ausência de questionamentos dos sujeitos entrevistados em relação à estrutura e relações sociais que dificultam as condições de trabalho, assim como a inexistência ou frágil politização dos informantes.

Vale ressaltar, também, percepções diferenciadas assumidas entre o público masculino e o publico feminino entrevistado. Percebe-se que, diante da condição de desemprego e de precarização, os homens demonstram menos resistência; as mulheres, por sua vez, questionam mais o que pode vir a ser a essência de todo o processo que vivenciam, inclusive informando com mais clareza como funciona a rede de influências entre instituição pública e mercado de trabalho.

Além disso, identifica-se que as mulheres "chefes de família" têm maiores dificuldades em encontrar estabilidade no mercado de trabalho diante da exigência dos afazeres domésticos, da necessidade de manter a família e a casa, associada às exigências e configurações do mercado de trabalho. Nota-se, ainda, nas entrevistas, a questão da dependência econômica da mulher em relação ao seu cônjuge, a ausência de perspectivas profissionais, a falta de autonomia diante da configuração familiar, a insuficiência ou baixa qualificação e profissionalização e, por fim, a baixa experiência profissional registrada em carteira.

Cabe destacar a postura diferenciada assumida entre as mulheres solteiras e chefes de família e os homens solteiros e chefes de família. Nesse caso, as situações de tristeza e desamparo frente ao desemprego são agravadas no público masculino, especialmente entre aqueles que relatam o abandono de lar por parte da esposa. Desse modo, os homens demonstram dificuldades em combinar assistência aos filhos, afazeres domésticos e busca do trabalho, verbalizando a necessidade de contratar uma empregada doméstica (sem registro em carteira, pois a maioria não tem condições de pagar um salário mínimo), ou ainda a possibilidade de encontrar uma nova companheira para dividir as tarefas. 


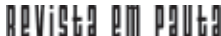

\} PRECARIZAÇÃO E FEMINIZAÇÃO - SALES, C. R. L.; MATHIS, A. A. \}

DOI: $10.12957 /$ rep.2015.21053

Apesar de as mulheres indicarem as mesmas dificuldades apontadas pelos homens, para elas o problema é encarado de forma mais realista, sem grandes idealizações. Finalmente, parece que os papéis com relação à divisão sexual e social do trabalho vêm sendo alterados, mesmo nas condições de precarização e vulnerabilidade expostas no trabalho. Na contemporaneidade, registra-se uma combinação de velhos e novos papéis nas relações sociais entre os sexos e a identificação de novos comportamentos sociais; os homens não ficam restritos apenas à função produtiva, assim como as mulheres não se limitam à função reprodutiva, sem inserção no mercado de trabalho. Contudo, apesar das inúmeras mudanças e conquistas do movimento feminista ao redor do mundo e dos inúmeros avanços sociais, na realidade atual, homens e mulheres convivem com problemas comuns em condições desiguais.

\section{Conclusão}

As conclusões da pesquisa ratificam e reiteram a estreita ligação entre a realidade local da precarização do trabalho, no município de Parauapebas, e a conjuntura mundial do modo de produção capitalista. Ou seja, a particularidade parauapebense compreende tendências mundiais do mercado de trabalho, associadas à funcionalidade histórica da região e da localidade, para a expansão de produção e lucratividade, discutida em outros textos já mencionados.

As manifestações do processo de precarização em tempos de reestruturação produtiva do capital são conduzidas pelo ideário neoliberal e a "especialização flexível" como modelo de organização e controle do trabalho. Na realidade, elas refletem a possibilidade concreta de fomentar a exploração do trabalho diante da necessidade de aumento da produtividade e competitividade para a maximização de lucros. Assim sendo, a difusão da informalidade, terceirização e empreendedorismo como alternativas ao desemprego, e discursos ideológicos, como empregabilidade, fortalecem a acumulação de capital e reforçam um conteúdo ideológico que se limita ao questionamento do acesso ao trabalho.

Há que se destacar, ainda, o processo de feminização do trabalho, que também passa a ser precarizado através do trabalhado atribuído ao sexo. Em tempos de precarização do mundo do trabalho, torna-se um grande desafio, especialmente por ser uma das peças fundamentais da produtividade e competitividade.

Essa realidade é melhor apreendida, a partir da caracterização do perfil dos trabalhadores submetidos aos cursos de qualificação pública no município de Parauapebas, ao serem analisados os discursos proferidos pelos representantes do poder público municipal, pelos habitantes do local e pelos próprios trabalhadores desempregados, os quais apresentam carac- 


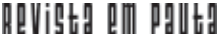

\} PRECARIZAÇÃO E FEMINIZAÇÃO - SALES, C. R. L.; MATHIS, A. A. |

DOI: $10.12957 /$ rep.2015.21053

terísticas que se aproximam a um conceito de precariado. No que se refere às mulheres entrevistadas, percebe-se que, apesar do agravante dos rebatimentos da divisão sociossexual ${ }^{18}$ do trabalho, elas demonstram mais resistência em relação aos homens em situação de desemprego e precarização, especialmente aqueles que são solteiros e chefes de família, os quais demandam a presença feminina para a conciliação de trabalho e afazeres domésticos.

Nesse sentido, importa destacar que não há, entre os entrevistados, uma reflexão e questionamento críticos das diretrizes e orientações dos organismos internacionais, como a Organização Internacional do Trabalho (OIT), levando ao esforço de obediência aos mesmos. Existe, porém, a reiteração de um conteúdo ideológico hegemônico de perpetuação e expansão do capital, através da ampliação do desemprego e da precarização do trabalho.

Diante do exposto, acredita-se que a aproximação com a temática permitiu entender como a condição de desemprego se assemelha às contribuições marxistas sobre a categoria "exército de reserva de mão de obra", que é funcional à ampliação do capital. Leva, ainda, a concluir e reiterar que, apesar de não haver um consenso na conceituação de precariado, a precariedade é funcional à manutenção do modo de produção capitalista porque possibilita a maximização de lucros.

\footnotetext{
${ }^{18} \mathrm{O}$ termo divisão sociossexual do trabalho vem sendo utilizado por Ricardo Antunes (2009) e/ou Claudia Mazzei Nogueira (2010).
} 


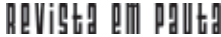

\} PRECARIZAÇÃO E FEMINIZAÇÃO - SALES, C. R. L.; MATHIS, A. A.\}

DOI: 10.12957/rep.2015.21053

\section{Referências}

ABREU, A. Especialização flexível e gênero: debates atuais. São Paulo em Perspectiva, n. 8, jan./mar. 1994.

ALENCAR, M. M. T. de; GRANEMANN, S. Ofensiva do capital e novas determinações do trabalho profissional. Revista Katálisis, Florianópolis, v. 12, n. 2, jul./dez. 2009.

ANTUNES, R. Século XXI: nova era da precarização estrutural do trabalho? In: ANTUNES, R; BRAGA, R. (org.). Infoproletários: degradação real do trabalho virtual. São Paulo: Boitempo. 2009.

BAKHTIN, M. M. Marxismo e filosofia da linguagem: problemas fundamentais do método sociológico da linguagem. São Paulo: Hucitec. 2010. BRAGA, R. A política do precariado: do populismo à hegemonia lulista. São Paulo: Boitempo. 2012.

BRANDÃO, H. H. N. Introdução à análise do discurso. São Paulo: Editora da Unicamp. 2012.

CASTEL, R. As metamorfoses da questão social. Uma crônica do salário. Rio de Janeiro: Editora Vozes. 2013.

DRUCK, G. Trabalho, precarização e resistências: novos e velhos desafios? Caderno CRH, Salvador, v. 24, n. 1. 2011.

HIRATA, H. A precarização e a divisão internacional e sexual do trabalho. Sociologias, Porto Alegre, ano 11, n. 21, jan./jun. 2009.

HIRATA, H.; KERGOAT, D. Novas configurações da divisão sexual do trabalho. Caderno de Pesquisa, v. 37, n. 132, set./dez. 2007.

IPEA - INSTITUTO DE PESQUISA E ECONOMIA APLICADA. Emprego e oferta qualificada de mão de obra no Brasil: impactos do crescimento econômico pós-crise. Comunicados do Ipea, n. 41. 2010. Disponível em: <http:/ /www.ipea.gov.br/portal/images/stories/PDFs/comunicado/100310_ comunicadoipea41.pdf>. Acesso em: 18 fev. 2014.

MARX, K. O capital: crítica da economia política. Livro I: o processo de produção do capital. São Paulo: Boitempo. 2013.

MATHIS, A. de A.; MATHIS, A. Reorientação de políticas públicas sociais e novas estratégias de desenvolvimento: um estudo realizado na região de Carajás/Pará. In: GOMES, V. L. B.; VIEIRA, A. C. de S.; NASCIMENTO, M. A. C. O avesso dos direitos: Amazônia e Nordeste em questão. Recife: Editora Universitária da UFPE. 2012.

MTE - MINISTÉRIO DO TRABALHO E EMPREGO. Cadastro geral de empregados e desempregados. Informações para o sistema público de emprego 


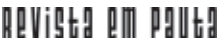

\} PRECARIZAÇÃO E FEMINIZAÇÃO - SALES, C. R. L.; MATHIS, A. A. \}

DOI: $10.12957 /$ rep.2015.21053

e renda - dados por município. 2014. Disponível em: <http://bi.mte.gov.br/ bgcaged/caged_isper/index.php>. Acesso em: 24 mar. 2014.

NOGUEIRA, Claudia Mazzei. As relações sociais de gênero no trabalho e na reprodução. Aurora, Marília, SP, ano IV, n. 6, p. 59-62, ago-2010. Disponível em: <http://www.marilia.unesp.br/Home/RevistasEletronicas/Aurora/ 6\%20NOGUEIRA,\%20Claudia\%20Mazzei.pdf>. Acesso em: 09 dez. 2014. OIT - ORGANIZAÇÃO INTERNACIONAL DO TRABALHO. O perfil dos trabalhadores e trabalhadoras na economia informal. Escritório da OIT no Brasil. Brasília: OIT. 2010.

SALES, C. Desemprego e Qualificação Profissional em Parauapebas no estado do Pará. Dissertação de Mestrado. Programa de Pós-Graduação em Serviço Social da Universidade Federal do Pará. Belém: 2015.

SALES, C; MATHIS, A.. Desemprego e qualificação profissional na região de Carajás-Pará. Revista Argumentum, v. 7, n. 1, jan./jun. 2015.

STANDING, G. El precariado. Barcelona: Ediciones de Passado y Presente. 2013.

Recebido em 30 de junho de 2015.

Aprovado para publicação em 15 de outubro de 2015.

DOI: $10.12957 /$ rep.2015.21053

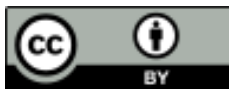

A Revista Em Pauta: Teoria Social e Realidade Contemporânea está licenciada com uma Licença Creative Commons Atribuição 4.0 Internacional. 